\title{
NUMERICAL INVESTIGATION OF MHD CASSON NANOFLUID FLOW TOWARDS A NON LINEAR STRETCHING SHEET IN PRESENCE OF DOUBLE-DIFFUSIVE EFFECTS ALONG WITH VISCOUS AND OHMIC DISSIPATION
}

\author{
Vinita Makkar ${ }^{1}$, Vikas Poply ${ }^{2,}{ }^{*}$, Rangoli Goyal ${ }^{1}$, Naresh Sharma $^{1}$
}

\begin{abstract}
The intention behind carrying out this research work is to analyze the steady Magnetohydrodynamic (MHD) boundary layer flow with Casson nanofluid in presence of Viscous and Ohmic dissipation effects towards a non-linear stretching sheet. Two phase representation of nanofluid studied the consequence of Brownian motion along with thermophoresis. The major purpose of study is to investigates the significant role of prominent fluid parameters especially yield stress, slip velocity, thermophoresis, Brownian motion, Eckert number, Schmidt number, magnetic parameter and non-linear stretching parameter on profile of velocity, temperature distribution and concentration while keeping the other parameters under study constant. Runge-Kutta Fehlberg (RKF) approach was adopted to numerically solve the non-linear governing equations and the linked boundary conditions by use of shooting technique. In present study, we use MATLAB for finding the final outcomes and relating the concluding results for local Nusselt number $-\theta_{\delta}^{\prime}(0)$ with extant outcomes in literature as a limiting case in the absence of thermophoresis and Brownian motion and an excellent agreement is noted. Over all the consequence of prominent fluid parameters are explained via graphs, whereas distinction of several valuable engineering quantities like skin friction coefficient, local Nusselt number and local Sherwood number are also tabulated. The finding of present study helps to control the rate of heat transportation as well as fluid velocity in any manufacturing processes and industrial applications to make desired quality of final product.
\end{abstract}

Keywords: Non-Linear Stretching Sheet, Brownian Motion, Thermophoresis, Casson Fluid, MHD, Viscous Dissipation, Ohmic Dissipation

\section{INTRODUCTION}

In various fields of science and technology rapid progress has urged the researchers to extend their study towards the regime of boundary layer flow over a stretching sheet. The boundary layer flow behavior towards a linearly or nonlinearly stretching sheet plays a significant role for solving engineering problems and possess vast applications in manufacturing and production processes including metal spinning, rubber sheet manufacturing, production of glass fibers, wire drawing, extrusion of polymer sheets, petroleum industries, polymer processing etc. In these cases, the final product of desired characteristics depends on the rate of cooling in the process and the process of stretching. The dynamics of the boundary layer fluid flow over a stretching surface originated from the pioneering work of Crane [1] and he examined the incompressible steady boundary layer fluid flow caused by stretching sheet which moves in its own plane with linear velocity due to the uniform stress applications. This problem is particularly interesting as Crane [1] obtained the exact solution of 2D Navier-Stokes equations. Afterthat, Gupta and Gupta [2] extend Crane [1] work over different mathematical geometries. Yoon et al. [3] studied the theoretical and experimental results using Coulomb friction model by considering punch-sheet interface. Also, Sarma and Rao [4] examined the viscoelastic fluid flow by considering stretched sheet. In view of this, Vajravelu [5] studied flow and heat transfer in a viscous fluid over a nonlinear stretching sheet without using the impact of viscous dissipation. Cortell [6] examined heat and fluid flow transportation over a nonlinear stretching sheet for two different types of thermal boundary conditions, prescribed surface temperature (PST) and constant surface temperature (CST). The influence of heat transfer on the stagnation point flow of a third-order fluid over a shrinking surface has been studied by Nadeem et al. [7]. Recently, Prasad et al.

This paper was recommended for publication in revised form by Regional Editor Muslum Arici

${ }^{1}$ School of Basic and Applied Sciences, GD Goenka University, Gurgaon-122103, Haryana, India.

${ }^{2}$ Department of Mathematics, KLP College, Rewari-123401, Haryana, India.

*E-mail address: vini252011makkar@gmail.com, vikaspoply@gmail.com, rangoligoyal@gmail.com, naresh.sharma2006@gmail.com Orcid id: 0000-0001-6377-0377, 0000-0002-1573-3210, 0000-0002-6631-493X, 0000-0001-8398-927X

Manuscript Received 04 May 2020, Accepted 17 July 2020 
[8] examined the mixed convection heat transfer aspects with variable fluid flow properties over a non-linear stretching surface.

Fluid heating and cooling are important in many industries such as power, manufacturing and transportation. Effective cooling techniques are greatly needed for cooling any sort of high energy device. Common heat transfer fluids such as water, ethylene glycol, and engine oil have limited heat transfer capabilities due to their low heat transfer properties. In contrast, metals have thermal conductivities up to three times higher than these fluids, so it is naturally desirable to combine the two substances to produce a heat transfer medium that behaves like a fluid, but has the thermal of a metal. Since last two decades, study of nanofluid has urged the researcher's attention due to their heat transportation rate. Nanofluid comes in existence when we add a small quantity of nano-sized $10^{-9}-10^{-7}$ particles to the base fluids. Low heat transportation fluids like fluorocarbons, glycol, deionized water, etc. have badly thermal conductivity and therefore deliberated necessary for heat transfer coefficient surrounded by heat transfer medium and surface. The nanoparticles are typically made up of metals $(\mathrm{Al}, \mathrm{Cu})$, nitrides $(\mathrm{AlN}, \mathrm{SiN})$, carbides $(\mathrm{Sic})$, oxides $\left(\mathrm{Al}_{2} \mathrm{O}_{3}\right)$, or nonmetals (carbon nanotubes, Graphite, etc.) and the base fluid (conductive fluid) is usually water or ethylene glycol. Also, it has been experimentally proved that rate of heat conduction of nanofluids is more than rate of heat conduction of the base fluids. The concept of nanofluid was initially proposed by Choi and Eastman [9] to indicate engineered colloids composed of nanoparticles dispersed in a base fluid. An MIT based comprehensive survey has been done by Buongiorno [10] for convective transportation in nanofluids by considering seven slip conditions that may produce a relative velocity within the base fluid and nanoparticles. Only two (Brownian motion and thermophoresis) out of these seven slip mechanisms were found to be important mechanisms. By adopting Buogiorno's model, Kuznetsov and Nield [11] explored the nanofluid boundary layer uniform convecting fluid flow.

In recent years, MHD fluid flow has gained researchers attention due to its controllable heat transfer rate. Magnetohydrodynamics (MHD) effect also play and influential role in controlling the rate of cooling as well as segregation of molten metal's from various non-metallic impurities. Magnetohydrodynamic (MHD) fluid flow has enormous utilization in manufacturing processes, even in the industrial areas as well. The terminology "Magnetohydrodynamic" is combination of three elementary terms magneto that stands for magnetic field, hydro that stands for fluid / liquid and dynamics that stands for evolution of particles. The existence of external magnetic field gives rise to Lorentz drag force which acts on the fluid, so potentially altering the characteristics of fluid flow especially velocity, temperature and concentration. Grouping of electromagnetism Maxwell's equation and fluid mechanics Navier's stokes equations therefore provides Magnetohydrodynamic (MHD) relation [12, 13]. Hayat et al. [14] studied the MHD fluid flow transportation over stretching surfaces. Later, the influence of viscous and Ohmic dissipation (i.e. joule heating) in nanofluid has been presented by Hussain et al. [15]. Vajravelu and Canon [16] studied the flow behavior of fluid towards a non-linear stretching sheet. Further, Matin et al. [17] analyzed the entropy effect in MHD nanofluid flow over stretching surface. Shawky et al. [18] studied the Williamson nanofluid flow in porous medium and he acknowledged that enhancement in non-Newtonian parameter escalates skin friction coefficient along with the rate of heat transfer. Basir et al. [19] examined the consequences of Peclet and Schmidt number in existence of partial slip towards a stretching surface. After that, rate of heat transfer along with partial slip condition was generalized by Pandey and Kumar [20]. Recently, Vinita and Poply [21] discussed MHD slip fluid flow of nanofluid in the existence of free stream velocity or outer velocity towards a stretching surface. Vinita et al. [22] studied MHD fluid flow with variable slip conditions over non-linear stretching surface. Furthermore, non-linearity effect towards the stretching surface under different physical circumstances has been examined by researchers in [6, 23-25].

Casson fluid is classified as a non-Newtonian fluid due to its rheological characteristics in relation to the shear stress-strain relationship. It behaves like an elastic solid at low shear strain and above a critical stress value; it behaves like a Newtonian fluid. A Casson fluid can best be described as a shear thinning liquid with infinite viscosity at zero shear rates, and zero viscosity at an infinite rate of shear. Some common examples of liquids that exhibit Casson fluid characteristics include tomato sauce, honey, soup, orange juice and human blood. In 1959, Casson fluid model was pioneered by Casson [26] for prognosis pigment-oil intermission flow. Furthermore, nanofluid boundary layer fluid flow over disparate geometries was premeditated by numerous researchers in [27-36]. Fluids behave as a solid, if the yield stress is more than applied shear stress. On the other hand, fluid behaves as a liquid for lesser yield stress. Kameshwaran et al. [37] investigated the dual solution in shrinking / stretching surface with Casson fluid flow to 
determine Lorentz force effect on heat and flow transportation. Also, Khan et al. [38] studied consequence of viscous dissipation on MHD nanofluid flow past a stretching sheet. Afify [39] investigated influence of partial slip chemical reaction and viscous dissipation over Casson nanofluid by considering stretched sheet.

Motivated by the above mentioned literature survey and widespread biological, industrial as well as engineering applications, it is of prime importance to explain the importance of mass and heat transportation of MHD flow past a non-linear stretching sheet with viscous and Ohmic dissipation effects by considering Navier velocity slip conditions. A precise review of already published research discloses that no such attempt has been made earlier even though the fruitfulness of thoughts and phenomenon explained in the present work can be expected to lead to the extremely productive interaction across disciplines. The mathematical difficulties and non-linearity appearing in the Casson nanofluid equations led us to use the numerical approach. The methodology adopted will be to solve the non-linear differential system through Runge-Kutta Fehlberg method. Behaviors of arising variables on concentration, temperature and velocity are graphically interpreted. The outcomes of current study reveal that non-linearity behavior of stretching sheet enhances the values of Sherwood number and skin friction coefficient while declination in value of Nusselt number is noticed. We give qualitative and quantitative comparisons with previously published work to show that our results have highly accurate. This study holds important industrial application, particularly in the field of extrusion where the fluid dispersed with particles is used to augment the strength and durability of the material.

\section{MATERIALS AND METHODS}

In present analysis, 2-D incompressible fluid flow in MHD Casson nanofluid over non-linear stretching sheet has been considered. Non-linear behavior generates flow and sheet is stretched in both direction of $x$ axis with stretching velocity $\boldsymbol{u}_{\boldsymbol{w}}=\boldsymbol{a} \boldsymbol{x}^{N}$, where $\boldsymbol{a}, \boldsymbol{x}$ and $\boldsymbol{N}$ denotes a constant, stretching surface coordinate and non-linear stretching parameter respectively. $\boldsymbol{T}_{\boldsymbol{w}}=\boldsymbol{T}_{\infty}+\boldsymbol{T}_{\mathbf{0}} \boldsymbol{x}^{\boldsymbol{m}}$ at $\boldsymbol{y}=\mathbf{0}$, where $\boldsymbol{T}_{\mathbf{0}}$ refers to the positive constant, $\boldsymbol{T}_{\infty}$ refers to the ambient temperature attained and $m$ refers to the physical parameter known as surface temperature parameter. Also, by introducing $\boldsymbol{m}=\mathbf{0}$, we have a special case of constant surface temperature (CST). Figure 1 represents the physical model of the current study. The continuity, momentum, energy and concentration equations of the incompressible Casson nanofluid boundary layer flow are as follows (see Buongiorno [10], Mustafa and Khan [40], Usman et al. [41], Gireesha et al. [42], Seth et al. [43])

$$
\begin{gathered}
\frac{\partial u}{\partial x}+\frac{\partial u}{\partial y}=0 \\
u \frac{\partial u}{\partial x}+v \frac{\partial u}{\partial y}=v\left(1+\frac{1}{\beta}\right) \frac{\partial^{2} u}{\partial y^{2}}-\frac{\sigma B^{2}}{\rho} u \\
u \frac{\partial T}{\partial x}+v \frac{\partial T}{\partial y}=\tau\left[D_{B} \frac{\partial C}{\partial y} \frac{\partial T}{\partial y}+\left(D_{T} / T_{\infty}\right)\left(\frac{\partial T}{\partial y}\right)^{2}\right]+\alpha_{m} \nabla^{2} T+\frac{\sigma B^{2}}{(\rho c)_{f}} u^{2}+\left(1+\frac{1}{\beta}\right) \frac{\mu}{(\rho c)_{f}}\left(\frac{\partial u}{\partial y}\right)^{2} \\
u \frac{\partial C}{\partial x}+v \frac{\partial C}{\partial y}=D_{B} \frac{\partial^{2} C}{\partial y^{2}}+\frac{D_{T}}{T_{\infty}} \frac{\partial^{2} T}{\partial y^{2}}
\end{gathered}
$$

Boundary conditions are given as:

$$
\begin{gathered}
u=u_{w}+u_{s}, v=0, T=T_{w}, C=C_{w} \text { at } y=0 \\
u \rightarrow 0, T \rightarrow T_{\infty}, C \rightarrow C_{\infty} \text { as } y \rightarrow \infty
\end{gathered}
$$

Here horizontal and vertical velocities are represented by $u$ and $v$, respectively. Also $v$ denotes kinematic viscosity, $\rho_{p}$ is the density of particle, $\alpha_{m}=\frac{k_{m}}{(\rho c)_{f}}$ is the thermal diffusivity, $a$ is a positive constant, $\tau=\frac{(\rho c)_{p}}{(\rho c)_{f}}$ defines a proportion of heat capacities, $\beta$ denotes Casson fluid parameter, $D_{T}$ reflects thermophoretic diffusion coefficient, $B$ 
is the magnetic field intensity, $D_{B}$ denotes Brownian diffusion coefficient, $\sigma$ represents electrical conductivity and $u_{s}$ refers to slip velocity that is considered to be proportional to wall stress described as:

$$
u_{s}=l\left(\frac{\partial u}{\partial y}\right)_{y=0}
$$

here, $l$ refers to the slip length which is proportionality constant for slip velocity. The fundamental equations (1) to (4) with boundary conditions (5) to (6) are transformed using similarity variables [25]

$$
\begin{array}{r}
u=a x^{N} f_{\delta}^{\prime}(\xi), v=-\sqrt{\frac{a v(N+1)}{2}} x^{\frac{N-1}{2}}\left(f_{\delta}(\xi)+\left(\frac{N-1}{N+1}\right) \xi f_{\delta}^{\prime}(\xi)\right) \\
\phi_{\delta}(\xi)=\frac{C-C_{\infty}}{C_{w}-C_{\infty}}, \theta_{\delta}(\xi)=\frac{T-T_{\infty}}{T_{w}-T_{\infty}}, \xi=y \sqrt{\frac{a(N+1)}{2 v}} x^{\frac{N-1}{2}}
\end{array}
$$

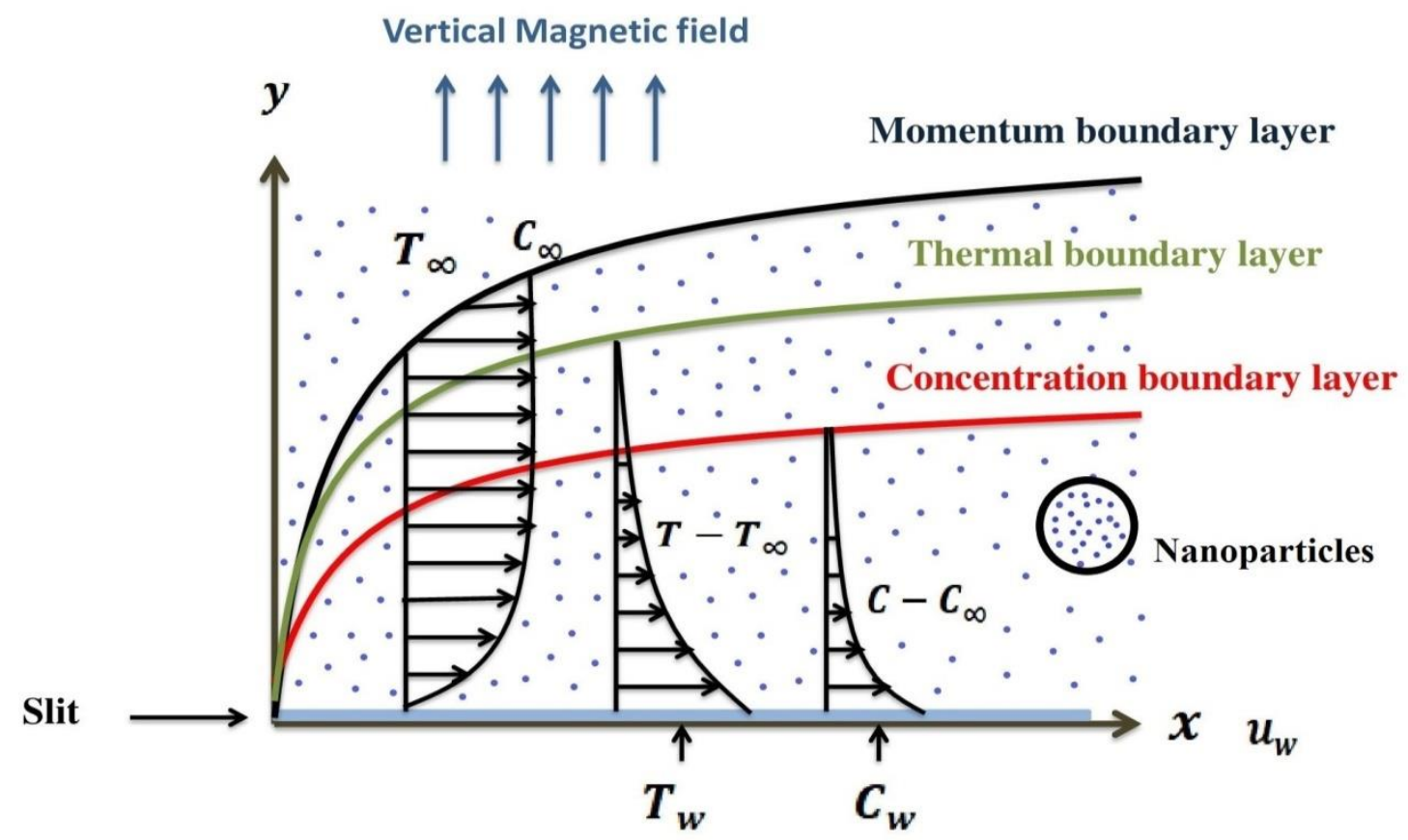

Figure 1: Physical model and coordinate system

Inserting equation (8) into equations (2) to (4), the governing equations (1)-(4) takes the form

$$
\begin{gathered}
\left(1+\frac{1}{\beta}\right) f_{\delta}^{\prime \prime \prime}+f_{\delta} f_{\delta}^{\prime \prime}-\left(\frac{2}{N+1}\right) M f_{\delta}^{\prime}-\left(\frac{2 N}{N+1}\right) f_{\delta}^{\prime 2}=0 \\
\frac{1}{\operatorname{Pr}} \theta_{\delta}^{\prime \prime}+f_{\delta} \theta_{\delta}^{\prime}-\left(\frac{2 m}{N+1}\right) f_{\delta}^{\prime} \theta_{\delta}+N b \theta_{\delta}^{\prime} \phi_{\delta}^{\prime}+N t \theta_{\delta}^{\prime 2}+\left(1+\frac{1}{\beta}\right) E c f_{\delta}^{\prime \prime 2}+\left(\frac{2}{N+1}\right) M S c f_{\delta}^{\prime 2}=0 \\
\phi_{\delta}^{\prime \prime}+\frac{1}{2} S c f_{\delta} \phi_{\delta}^{\prime}+\frac{N t}{N b} \theta_{\delta}^{\prime \prime}=0
\end{gathered}
$$

The relevant boundary conditions are reduced to 
Journal of Thermal Engineering, Research Article, Vol. 7, No. 2, Special Issue 13, pp. 1-17, February, 2021

$$
\begin{gathered}
f_{\delta}(\xi)=0, f_{\delta}^{\prime}(\xi)=1+d f_{\delta}^{\prime \prime}(\xi), \theta_{\delta}(\xi)=1 \text { and } \phi_{\delta}(\xi)=1 \text { at } \xi=0 \\
f_{\delta}^{\prime}(\xi) \rightarrow 0, \phi_{\delta}(\xi) \rightarrow 0 \text { and } \theta_{\delta}(\xi) \rightarrow 0 \text { as } \xi \rightarrow \infty
\end{gathered}
$$

where prime denotes derivative with respect to $\xi$ and the key crucial parameters are defined by:

$$
\begin{gathered}
M=\frac{\sigma B^{2}}{a x^{N-1}}, N t=\frac{(\rho c)_{p} D_{T}\left(T_{w}-T_{\infty}\right)}{(\rho c)_{f} v T_{\infty}}, S c=\frac{v}{D_{B}}, \operatorname{Pr}=\frac{v}{\alpha} \\
d=l \sqrt{\frac{a(N+1) x^{N-1}}{2 v}}, E c=\frac{u_{w}^{2}}{C_{p}\left(T_{w}-T_{\infty}\right)} \text { and } N b=\frac{(\rho c)_{p} D_{B}\left(C_{w}-C_{\infty}\right)}{(\rho c)_{f} v}
\end{gathered}
$$

Here $M$ is the magnetic parameter, $N t$ is the thermophoresis parameter, $S c$ is the Schmidt number, $P r$ is Prandtl number, $d$ is the velocity slip parameter, $E c$ is the Eckert number and $N b$ is the Brownian motion parameter. It is notes significantly that this boundary value problem condenses into the classical problem of mass, heat and flow transportation because of the stretching surface in a viscous fluid when $N=1$ and in equations (10) and (11); $N b, N t$ are zero (The boundary value problem is of no physical significance and condenses into the classical problem for becomes ill-posed).

It is worth mentioning that equation (9) with the boundary conditions (12), (13); where $N=0$, are the classical Blasius flat-plate flow problem and a comprehensive numerical analysis of that problem has been conceded by the author of this work. For the linear stretching problem (i.e., when $N=1$ ), the exact solution for $f_{\delta}$ is $f_{\delta}(\xi)=1-e^{-\xi}$, which was first obtained by the great scientist Crane [1] and this exact solution is unique, while for the non-linear stretching problem (i.e., when $N \neq 1$ ), there is no exact solution. Also, the physical quantities of interest skin friction coefficient, local Nusselt number and local Sherwood number are respectively defined as:

$$
C f_{x}=\frac{\tau}{\rho u_{w}^{2}}, N u_{x}=\frac{x q_{w}}{k\left(T_{w}-T_{\infty}\right)} \text { and } S h_{x}=\frac{x q_{m}}{D_{B}\left(C_{w}-C_{\infty}\right)}
$$

where $\tau_{w}, q_{w}$ and $q_{m}$ are wall shear stress, local heat flux and local mass flux at the stretching surface serially given as:

$$
\begin{gathered}
\tau_{w}=\mu a x^{\frac{3 N-1}{2}} \sqrt{\frac{a(N+1)}{2 v}}\left(1+\frac{1}{\beta}\right) f_{\delta}^{\prime \prime}(0) \\
q_{w}=-k\left(T_{w}-T_{\infty}\right) x^{\frac{N-1}{2}} \sqrt{\frac{a(N+1)}{2 v}} \theta_{\delta}^{\prime}(0) \\
\boldsymbol{q}_{\boldsymbol{m}}=-\boldsymbol{D}_{\boldsymbol{B}}\left(\boldsymbol{C}_{\boldsymbol{w}}-\boldsymbol{C}_{\infty}\right) \boldsymbol{x}^{\frac{N-\mathbf{1}}{2}} \sqrt{\frac{\boldsymbol{a}(\boldsymbol{N}+\mathbf{1})}{2 v}} \boldsymbol{\phi}_{\delta}^{\prime}(\mathbf{0})
\end{gathered}
$$

The system of partial differential equations (9)-(11) are highly non-linear, hence cannot be solved by using analytical methods. The variational Runge Kutta Fehlberg method has been implemented.

\section{NUMERICAL PROCEDURE}

The system of differential equations (9)-(11) are not solved analytically due to extremely non-linear behaviour. To solve this system of non-linear differential equations (9)-(11) together with boundary conditions (12)-(13), we adopt Runge Kutta Fehlberg approach (numerical procedure) and solution is investigated against the variation in Eckert 
number $E c$, Casson fluid parameter $\beta$, velocity slip parameter $d$, thermophoresis $N t$, Brownian motion parameter $N b$, Schmidt number $S c$, non-linear stretching parameter $N$ and magnetic parameter $M$. The value of horizontal axis - $\xi$ is chosen in such a way that a velocity, temperature and concentration profiles asymptotically tends to the boundary condition. All the simulations are conceded with $\xi_{\max }=10$. However, to illustrate the characterization of curve efficiently, much lower values of $\xi$ are used. The major advantage of shooting method over many numerical techniques is that it has fifth order truncation error. Also the process of solution computation is easier as compared to other numerical methods or techniques. For this purpose, the coupled differential equations (9)-(11) are rehabilitated into a set of seven initial value problems by launching the new set of dependent variables $s_{i}(\mathrm{i}=1$ to 7$)$ as:

$$
\begin{gathered}
s_{1}^{\prime}=s_{2} \\
s_{2}^{\prime}=s_{3} \\
s_{3}^{\prime}=\frac{1}{\left(1+\frac{1}{\beta}\right)}\left[-s_{1} s_{3}+\frac{2 N}{N+1}\left(s_{2}^{2}-\lambda^{2}\right)+\frac{2}{N+1} M\left(s_{2}-\lambda\right)\right] \\
s_{4}^{\prime}=s_{5} \\
s_{5}^{\prime}=-\operatorname{Pr}\left[s_{1} s_{5}+\left(\frac{2 m}{n+1}\right) s_{2} s_{4}+N b s_{5} s_{7}+N t s_{5}^{2}+\left(1+\frac{1}{\beta}\right) E c s_{3}^{2}-\operatorname{Pr}\left(\frac{2}{N+1}\right) M E c s_{2}^{2}\right] \\
s_{6}^{\prime}=s_{7} \\
s_{7}^{\prime}=\frac{N t}{N b} \operatorname{Pr}\left[s_{1} s_{5}-\left(\frac{2 m}{N+1}\right) s_{2} s_{4}+N b s_{5} s_{7}+N t s_{5}^{2}+\left(1+\frac{1}{\beta}\right) E c s_{3}^{2}\right]-\frac{1}{2} s_{1} s_{7} S c+\frac{N t}{N b} \operatorname{Pr}\left(\frac{2}{N+1}\right) M E c s_{2}^{2}
\end{gathered}
$$

The subjected boundary conditions (12) and (13) are reduced to

Where

$$
\begin{gathered}
s_{1}=0, s_{2}=1+d s_{3}, s_{6}=1, s_{4}=1 \text { at } \xi=0 \\
\text { and } s_{2}=\lambda, s_{6}=0, s_{4}=0 \text { as } \xi \rightarrow \infty
\end{gathered}
$$

$$
\begin{array}{r}
s_{1}=f_{\delta}, s_{2}=f_{\delta}^{\prime}, s_{3}=f_{\delta}^{\prime \prime}, s_{3}^{\prime}=f_{\delta}^{\prime \prime \prime} \\
s_{4}=\theta_{\delta}, s_{5}=\theta_{\delta}^{\prime}, s_{5}^{\prime}=\theta_{\delta}^{\prime \prime} \\
s_{6}=\phi_{\delta}, s_{7}=\phi_{\delta}^{\prime}, s_{7}^{\prime}=\phi_{\delta}^{\prime \prime}
\end{array}
$$

To solve the above system of differential equations along with the boundary conditions, shooting technique is implemented which consists of the following steps [15]:

1. Choose the appropriate value for the limit $\xi_{\infty}$.

2. Next important step is to select good initial approximations for $s_{3}(0), s_{5}(0)$ and $s_{7}(0)$.

3. Therefore the above system of differential equations (19)-(25) is converted into the initial value problem and then it is solved with the help of Runge-Kutta-Fehlberg method.

4. The computed solution will converge if absolute difference of given and computed values of $s_{2}(\infty), s_{4}(\infty)$ and $s_{6}(\infty)$ is absolutely less than tolerance error i.e. $10^{-6}$.

5. If these differences are greater than tolerance error, then guessed values of $s_{3}(0), s_{5}(0)$ and $s_{7}(0)$ are modified with the help of Newton's method.

This procedure is repeated until the computed solution meets the convergence criteria as shown in Figure 2. 


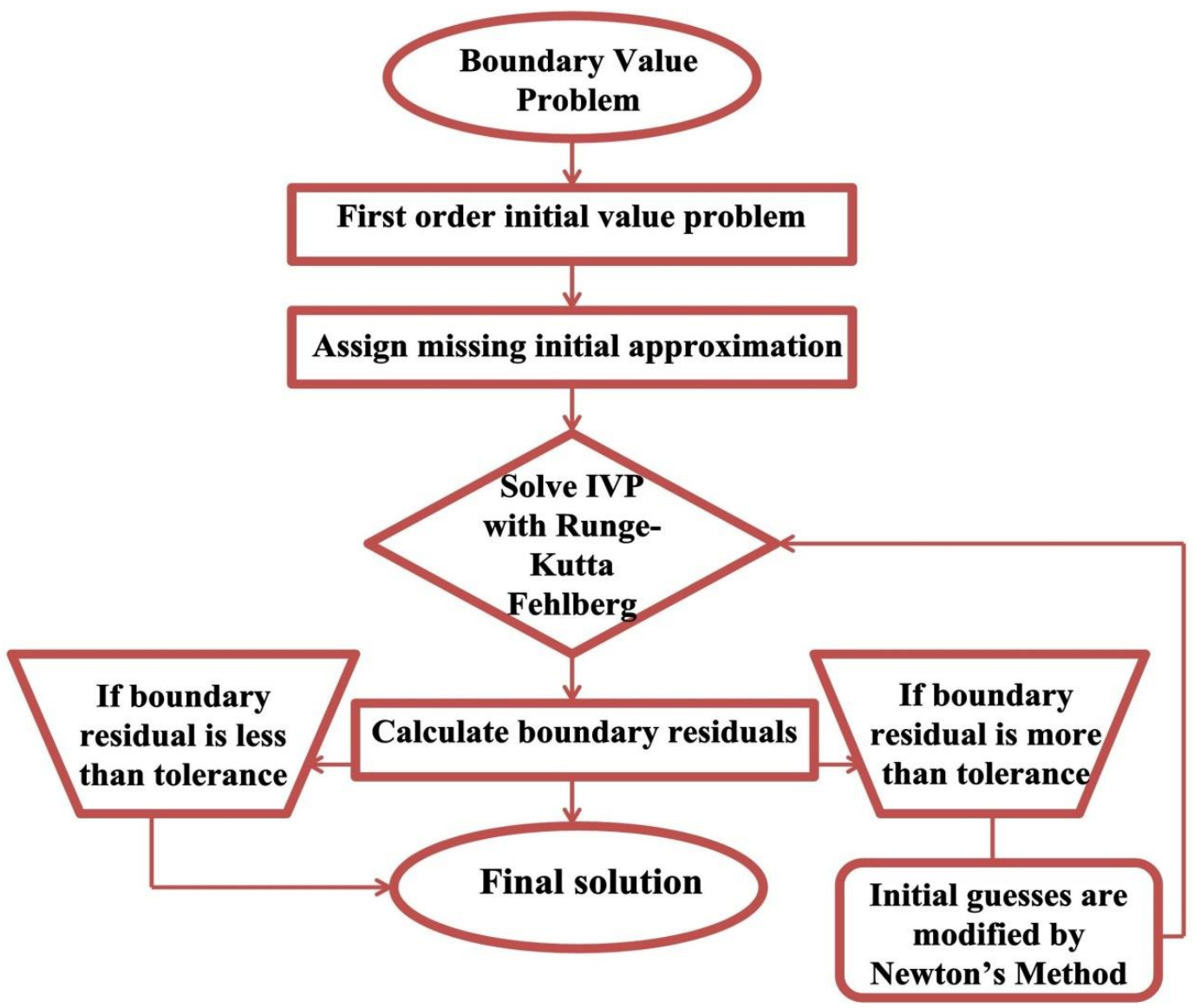

Figure 2: Flow chart of numerical technique

\section{Validation of Numerical Scheme}

In current study, we use RKF method for finding the final outcomes and the adopting numerical process (i.e. shooting technique) is valid. We take constant vale of nanoparticle concentration and temperature at the boundary. For the purpose of verification of the code, we compare our results for local Nusselt number with those of Rana and Bhargava [25] and Cortell [6] for different values of Prandtl number $\mathrm{Pr}$ and non-linear stretching parameter $N$ by taking the values of Brownian motion parameter $N b$ and thermophoresis parameter $N t$ as zero as shown via Table 1. A very good agreement in the results can be seen which strengthens the reliability of the present work (see Figures 3 and 4).

Table 1: Comparison of results for local Nusselt number $-\theta_{\delta}^{\prime}(0)$ with $N t=N b=0$ and different values of Prandtl number $\operatorname{Pr}$ and non-linear stretching parameter $N$

\begin{tabular}{|c|c|c|c|c|}
\hline$P r$ & $N$ & Rana and Bhargava [25] & Cortell [6] & Present results \\
\hline \multirow{4}{*}{1.0} & 0.1 & 0.6101 & 0.6102 & 0.6102 \\
& 0.5 & 0.5955 & 0.5952 & 0.5952 \\
& 1.5 & 0.5756 & 0.5745 & 0.5747 \\
& 3.0 & 0.5660 & 0.5644 & 0.5647 \\
\hline \multirow{4}{*}{5.0} & 0.1 & 1.5683 & 1.6071 & 1.6077 \\
& 0.5 & 1.5512 & 1.5867 & 1.5867 \\
& 1.5 & 1.5269 & 1.5574 & 1.5576 \\
& 3.0 & 1.5144 & 1.5423 & 1.5431 \\
\hline
\end{tabular}




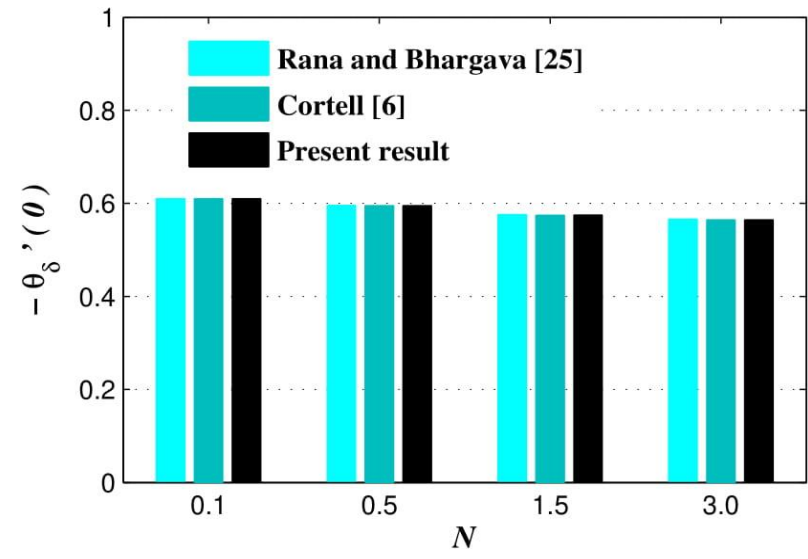

Figure 3: Bar graph showing comparison of local Nusselt number for non-linear stretching sheet when $\operatorname{Pr}=1.0$

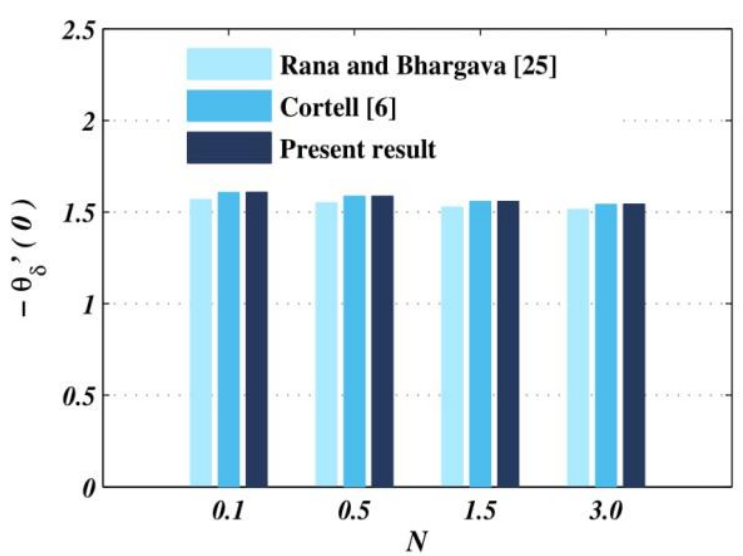

Figure 4: Bar graph showing comparison of local Nusselt number for non-linear stretching sheet when $\operatorname{Pr}=5.0$

\section{RESULTS AND DISCUSSION}

Present study finds numerical solution of differential equations (9) to (11) subjected to the boundary conditions (12) to (13) that are computed using RKF method by applying shooting technique. The main reason behind to solve the present problem are to determine the impact of prominent fluid parameters namely Eckert number $E c$, Casson fluid parameter $\beta$, velocity slip parameter $d$, thermophoresis $N t$, Brownian motion parameter $N b$, Schmidt number $S c$, non-linear stretching parameter $N$ and magnetic parameter $M$ on $f_{\delta}^{\prime}(0), \theta_{\delta}(0)$ and $\phi_{\delta}(0)$. Physically, the values of prominent physical parameters are taken as $\beta=0.4, d=0.1, N b=0.3, E c=0.4, N t=0.3, S c=$ $1.5, N=M=1.0, m=1.0 \quad$ and $P r=5.0$. Table 2 demonstrate the impact of fluid parameters $\beta, d N b, N t, E c, S c, M$ and $N$ on skin friction coefficient $f_{\delta}^{\prime \prime}(0)$, local Nusselt number $-\theta_{\delta}^{\prime}(0)$ and local Sherwood number $-\phi_{\delta}^{\prime}(0)$ by taking fixed entries of fluid parameters Prandtl number, $\operatorname{Pr}$ as 5.0 and surface temperature parameter $m$ as 1.0 and an excellent convergence has been achieved in current problem.

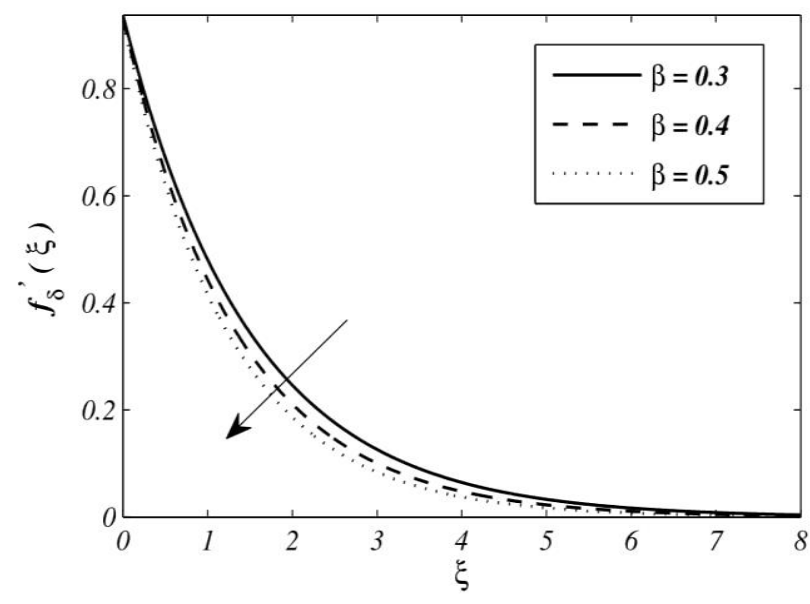

Figure 5: Impact of Casson fluid parameter $\beta$ on velocity profile $f_{\delta}^{\prime}(\xi)$ for $m=1.0, \operatorname{Pr}=5.0, d=$ $0.1, N b=0.3, N t=0.3, E c=0.1, S c=1.5, M=$ 1.0 and $N=1.0$

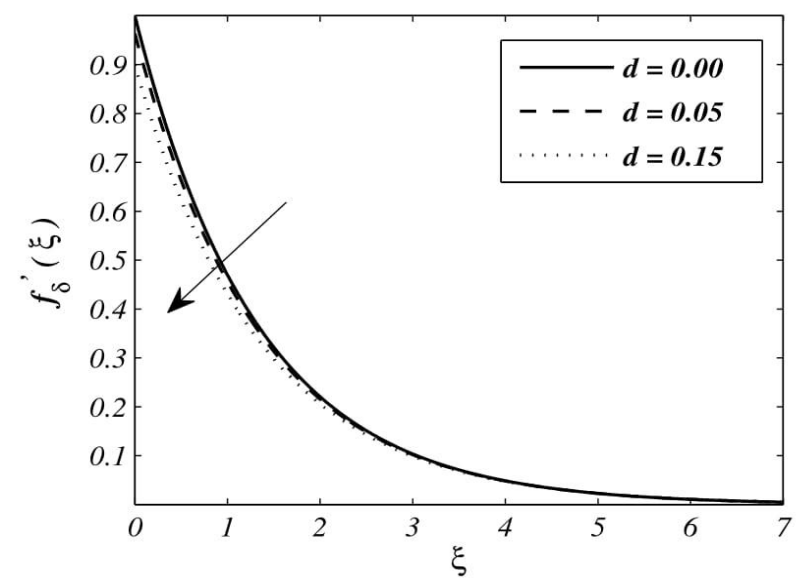

Figure 6: Impact of velocity slip parameter $d$ on velocity profile $f_{\delta}^{\prime}(\xi)$ for $m=1.0, \operatorname{Pr}=5.0, \beta=$ $0.4, N t=N b=0.3, E c=0.1, S c=1.5, N=$ $M=1.0$ 
Journal of Thermal Engineering, Research Article, Vol. 7, No. 2, Special Issue 13, pp. 1-17, February, 2021

Table 2: Values of skin friction coefficient $f_{\delta}^{\prime \prime}(0)$, local Nusselt number $-\theta_{\delta}^{\prime}(0)$ and local Sherwood number $-\phi_{\delta}^{\prime}(0)$ for crucial fluid parameters $\beta, d, N b, N t, E c, S c, M$ and $N$ with fixed entries of $\operatorname{Pr}=5.0$ and $m=1.0$

\begin{tabular}{|c|c|c|c|c|c|c|c|c|c|c|}
\hline$\beta$ & $d$ & $N b$ & $N t$ & $E c$ & $S c$ & $M$ & $N$ & $f_{\delta}^{\prime \prime}(0)$ & $-\theta_{\delta}^{\prime}(0)$ & $-\phi_{\delta}^{\prime}(0)$ \\
\hline 0.3 & 0.1 & 0.1 & 0.2 & 0.4 & 1.5 & 1.0 & 1.0 & -0.62674 & 0.72369 & -0.41288 \\
0.4 & & & & & & & & -0.69140 & 0.78127 & -0.55822 \\
0.5 & & & & & & & & -0.74178 & 0.82246 & -0.66610 \\
\hline 0.4 & 0.00 & 0.1 & 0.2 & 0.4 & 1.5 & 1.0 & 1.0 & -0.75593 & 0.65356 & -0.27946 \\
& 0.05 & & & & & & & -0.72203 & 0.72255 & -0.42910 \\
& 0.15 & & & & & & & -0.66354 & 0.83156 & -0.67041 \\
\hline 0.4 & 0.1 & 0.05 & 0.2 & 0.4 & 1.5 & 1.0 & 1.0 & -0.69140 & 0.82355 & -1.77998 \\
& & 0.10 & & & & & & -0.69140 & 0.78127 & -0.55822 \\
& & 0.15 & & & & & & -0.69140 & 0.74045 & -0.15292 \\
\hline 0.4 & 0.1 & 0.1 & 0.2 & 0.4 & 1.5 & 1.0 & 1.0 & -0.69140 & 0.78127 & -0.55822 \\
& & & 0.3 & & & & & -0.69140 & 0.73298 & -0.95811 \\
& & & 0.4 & & & & & -0.69140 & 0.68790 & -1.28267 \\
\hline 0.4 & 0.1 & 0.1 & 0.2 & 0.0 & 1.5 & 1.0 & 1.0 & -0.69140 & 2.18627 & -3.19235 \\
& & & & 0.1 & & & & -0.69140 & 1.83840 & -2.54049 \\
& & & & 0.2 & & & & -0.69140 & 1.48829 & -1.88419 \\
\hline 0.4 & 0.1 & 0.1 & 0.2 & 0.4 & 1.1 & 1.0 & 1.0 & -0.69140 & 0.81074 & -0.78101 \\
& & & & & 1.4 & & & -0.69140 & 0.78800 & -0.60993 \\
& & & & & 1.7 & & & -0.69140 & 0.76889 & -0.46155 \\
\hline 0.4 & 0.1 & 0.1 & 0.2 & 0.4 & 1.5 & 0.8 & 1.0 & -0.65763 & 0.95086 & -0.85564 \\
& & & & & & 1.0 & & -0.69140 & 0.78127 & -0.55882 \\
& & & & & & & & -0.72329 & 0.61783 & -0.27004 \\
\hline 0.4 & 0.1 & 0.1 & 0.2 & 0.4 & 1.5 & 1.0 & 1.0 & -0.69140 & 0.78127 & -0.55822 \\
& & & & & & & 1.1 & -0.68832 & 0.75748 & -0.50892 \\
& & & & & & & 1.2 & -0.68551 & 0.73563 & -0.46362 \\
\hline
\end{tabular}

Figure 5 illustrates the velocity profile $f_{\delta}^{\prime}(\xi)$ variation against Casson fluid parameter $\beta(0.3,0.4,0.5)$. A decrease in velocity profile is noticed for higher Casson fluid parameter $\beta$. This graph elaborates that enhancement in the value of Casson fluid parameter $\beta$ will declines yield stress that hurdles the free movement of fluid particles and hence boundary layer thickness reduces. Thus, fluid velocity decreases. Consequently, declination in the value of skin friction coefficient $C f_{x}$ is observes as seen in Table 2. Figure 6 deliberates the behavior of velocity variation for prominent values of velocity slip parameter $d(0.00,0.05,0.15)$. This graph exhibits that fluid velocity as well as slip velocity increases for higher values velocity slip parameter $d$. This is due to the presence of velocity slip parameter. Hence, velocity of fluid flow close to the surface of sheet disparate the velocity of stretching sheet. Also, Table 2 gives valuable information that larger value of velocity slip parameter $d$ falls down the numeric value of skin friction coefficient in absolute sense. 


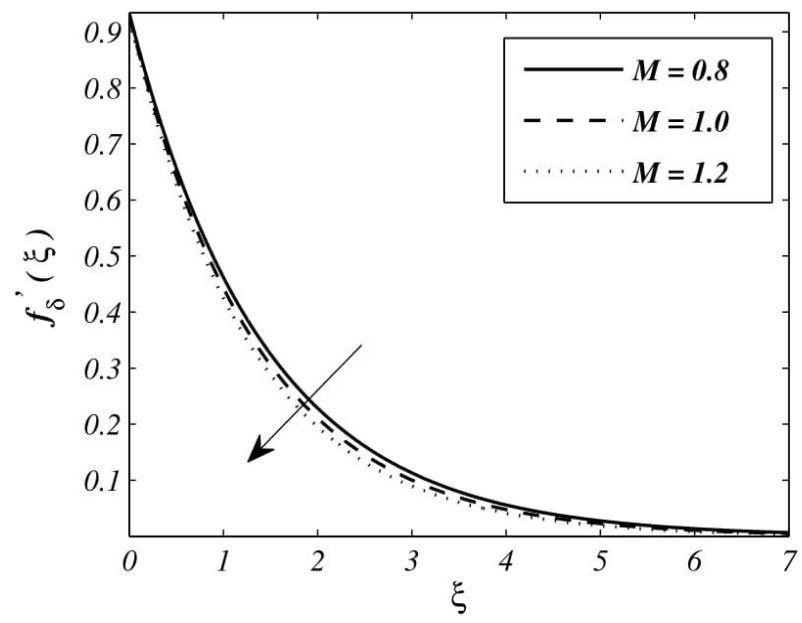

Figure 7: Impact of magnetic parameter $M$ on velocity profile $f_{\delta}^{\prime}(\xi)$ for $m=1.0, \operatorname{Pr}=5.0, \beta=0.4, d=$ $0.1, N b=0.3, N t=0.3, S c=1.5, E c=0.1$ and $N=1.0$

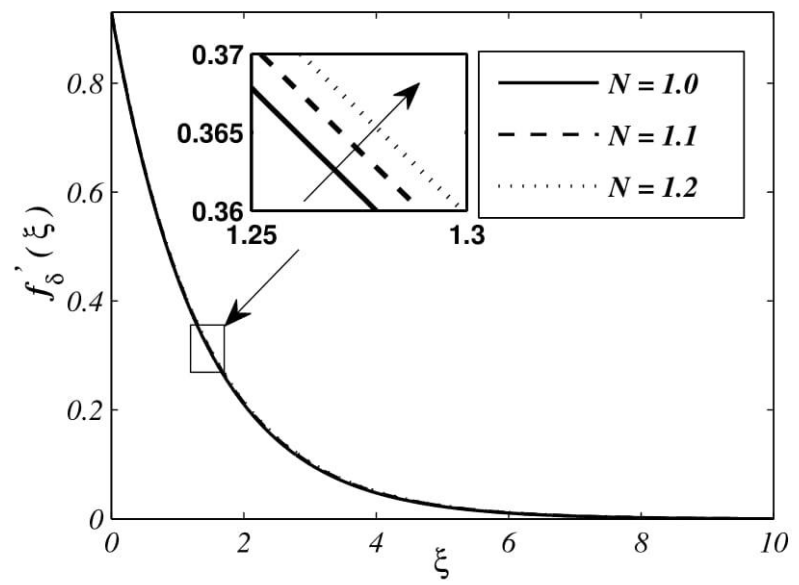

Figure 8: Impact of non linear stretching parameter $N$ on velocity profile $f_{\delta}^{\prime}(\xi)$ for $m=1.0, \operatorname{Pr}=5.0, \beta=$ $0.4, N t=N b=0.3, E c=0.1, d=0.1, S c=$ $1.5, M=1.0$

Figure 7 manifests variation in fluid velocity against magnetic parameter $M(0.8,1.0,1.2)$. This figure shows that existence of magnetic parameter $M$ resists the fluid particle to move freely and main reason behind the resistance is that magnetic parameter $M$ produces Lorentz force and this magnetism behavior can be adopted for controlling the fluid movement. Thus, enhancement in the value of magnetic parameter $M$ causes the declination of velocity distribution. Figure 8 portraits the nanofluid velocity variation under the influence of non-linear stretching parameter $N(1.0,1.1,1.2)$. This figure prevailed that nanofluid velocity decreases due to more interruption surrounded by different layers of fluid and this is because of presence of non-linear stretching parameter $N$. Consequently, velocity gradient increases i.e. increment in $f_{\delta}^{\prime}(\xi)$ is observed that can be seen in Table 2.

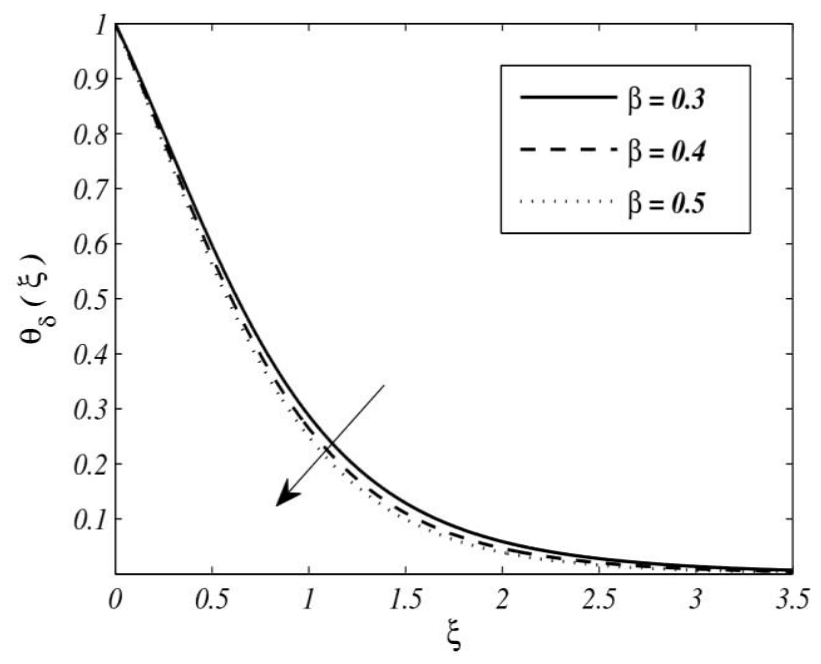

Figure 9: Impact of Casson fluid parameter $\beta$ on temperature profile $\theta_{\delta}(\xi)$ for $m=1.0, \operatorname{Pr}=$ 5.0, $d=0.1, N t=N b=0.3, E c=0.1, S c=$ $1.5, N=M=1.0$

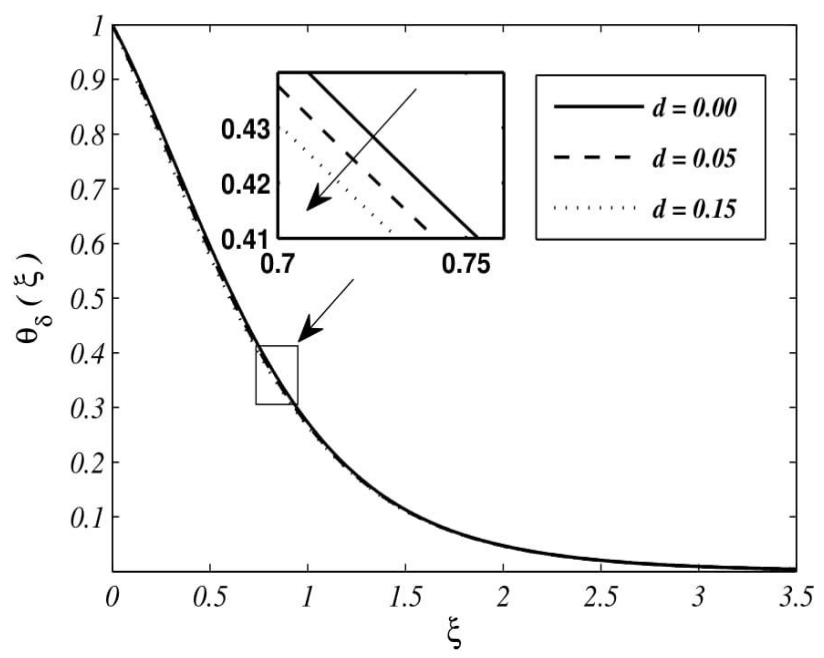

Figure 10: Impact of velocity slip parameter $d$ on temperature profile $\theta_{\delta}(\xi)$ for $m=1.0, \operatorname{Pr}=$ $5.0, \beta=0.4, N t=N b=0.3, E c=0.1, S c=$ 1.5, $N=M=1$. 
Figure 9 depicts the behavior of Casson fluid parameter $\beta(0.3,0.4,0.5)$ on temperature distribution $\theta_{\delta}(\xi)$. This figure indicates that as Casson fluid parameter $\beta$ increases, fluid temperature decreases and this graph elaborates that enhancement in the value of Casson fluid parameter $\beta$ declines velocity that will reduce the heat transfer rate and hence fluid temperature declines. Additionally, a slight decrease in temperature is noticed as seen in Figure 9. Consequently, enhancement in local Nusselt number Nux is noticed that can be seen in Table 2.

Figure 10 shows the variation of velocity slip parameter $d(0.00,0.05,0.15)$ on temperature distribution $\phi_{\delta}(\xi)$. This graph shows that as velocity slip parameter $d$ rises, boundary layer thickness declines and this is due to the presence of magnetic field as well as thermal jump of the fluid particles. Thus, nanoparticle temperature distribution declines for higher values of velocity slip parameter and hence rate of heat transportation increases that will increases the value of local Nusselt number.

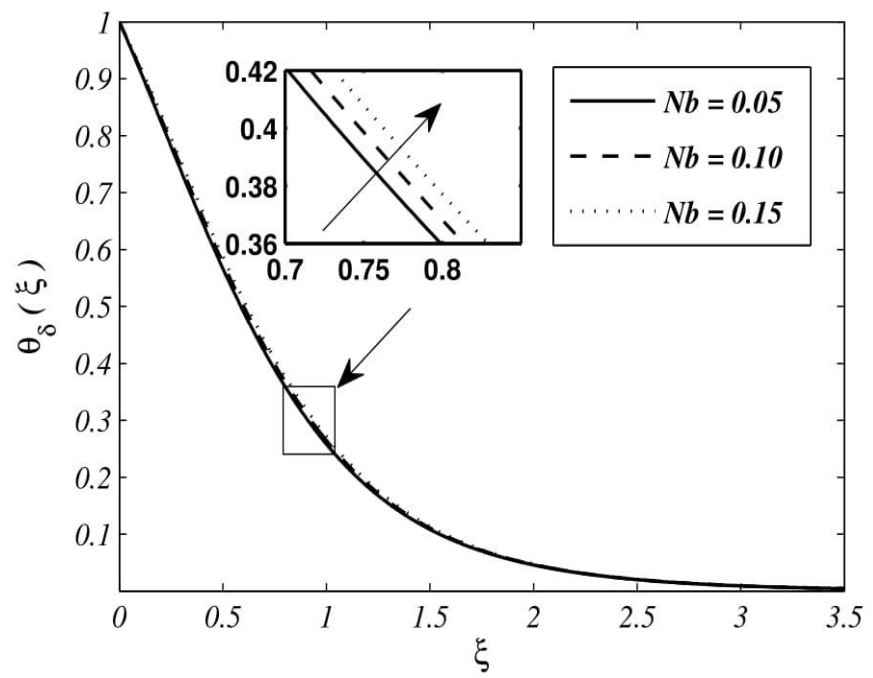

Figure 11: Impact of Brownian motion parameter $\mathrm{Nb}$ on temperature profile $\theta_{\delta}(\xi)$ for $m=1.0, P r=$ $5.0, \beta=0.4, d=0.1, S c=1.5, E c=0.1, N t=$ $0.3, M=1.0$ and $N=1.0$

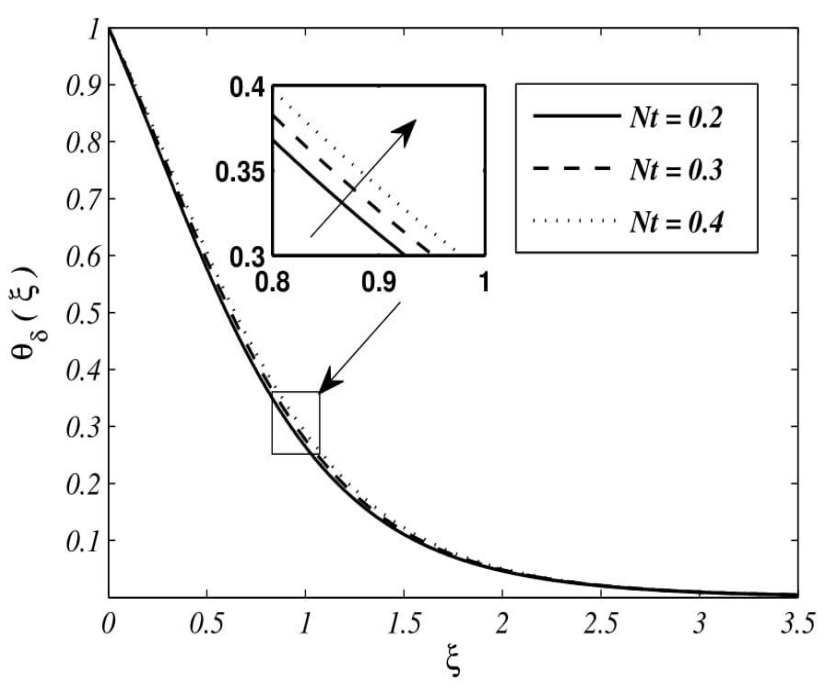

Figure 12: Impact of thermophoresis parameter $N t$ on temperature profile $\theta_{\delta}(\xi)$ for $m=1.0, \operatorname{Pr}=$ $5.0, \beta=0.4, d=0.1, N b=0.3, E c=0.1, S c=$ $1.5, N=M=1.0$

Figure 11 examines temperature distribution variation against the fluid parameter Brownian motion parameter $\mathrm{Nb}(0.05,0.10,0.15)$. The striking of atoms or molecules of the fluid particles with each other will create an arbitrary motion called Brownian motion of suspended (pendulous) particles and that will enhances width of boundary layer. Hence, fluid temperature increases for higher Brownian motion parameter $N b$ and in consequence local Nusselt number decreases.

Figure 12 deliberates the impact of fluid temperature under the consequence of thermophoresis parameter $N t(0.2,0.3,0.4)$. Temperature gradient falls down for higher values of thermophoresis parameter $N t$ that result in reduction of conduction of nanoparticles. Thus, width of boundary layer enhances due to reallocation of ultrafine particles from hotter to colder part and hence, temperature enhances for higher thermophoresis parameter $N t$ that can be seen in Figure 12. Figure 13 demonstrate fluid temperature variation against Eckert number $E c(0.0,0.1,0.2)$. A dimensionless quantity $E c$ is the fraction of advective transportation and heat dissipation potential. As Eckert number $E c$ enhances, thermal buoyancy effect raises that results in increasing temperature and that is the main reason behind the conversion of kinetic energy into thermal energy. Hence, fluid temperature enhances because of this conversion effect. Consequently, declination in Nusselt number $N u_{x}$ is noticed that can be seen via Table 2 . Figure 14 reflects variation of temperature distribution against magnetic parameter $M$. With an increase in magnetic parameter $M$, velocity profile decreases because of generation of Lorentz force that consequently intensify the boundary thickness and rate of heat transportation and hence fluid temperature enhances as shown via Figure 14. 


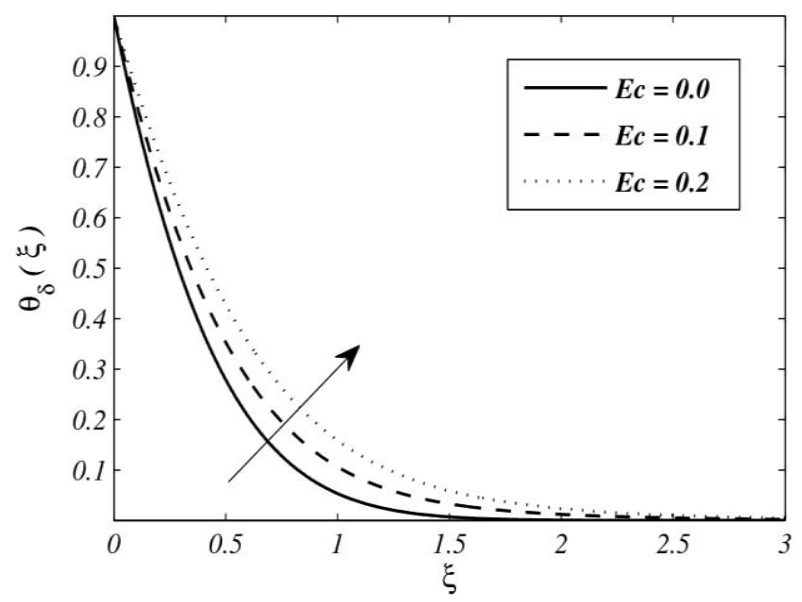

Figure 13: Impact of Eckert number $E c$ on temperature profile $\theta_{\delta}(\xi)$ for $m=1.0, \mathrm{Pr}=$ $5.0, \beta=0.4, d=0.1, S c=1.5, N b=0.3, N t=$ $0.3, M=1.0$ and $N=1.0$

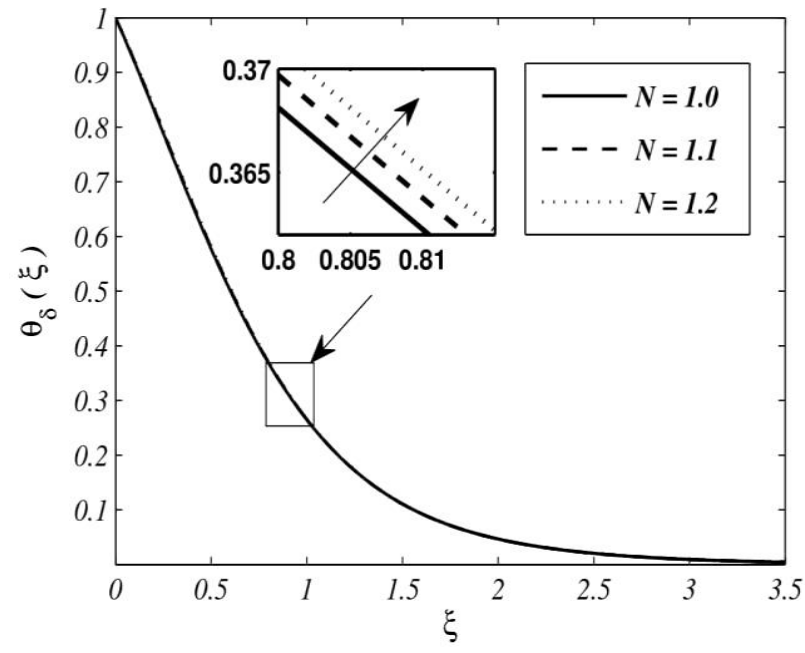

Figure 15: Impact of non-linear stretching parameter $N$ on temperature profile $\theta_{\delta}(\xi)$ for $\operatorname{Pr}=5.0, m=$ $1.0, \beta=0.4, d=0.1, S c=1.5, E c=0.1, N t=$ $N b=0.3$ and $M=1.0$

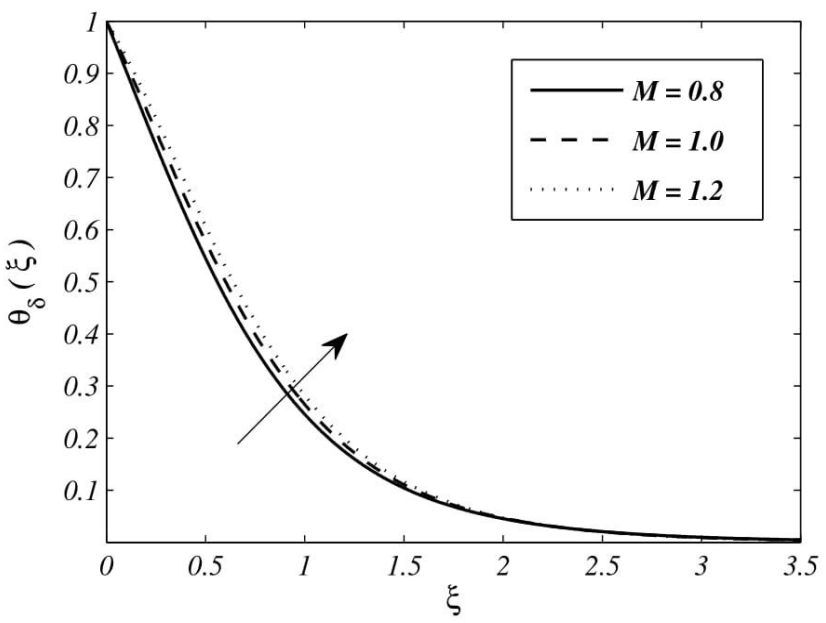

Figure 14: Impact of magnetic parameter $M$ on temperature profile $\theta_{\delta}(\xi)$ for $m=1.0, \operatorname{Pr}=5.0, \beta=$ $0.4, d=0.1, N b=N t=0.3, E c=0.1, S c=$ $1.5, N=1.0$

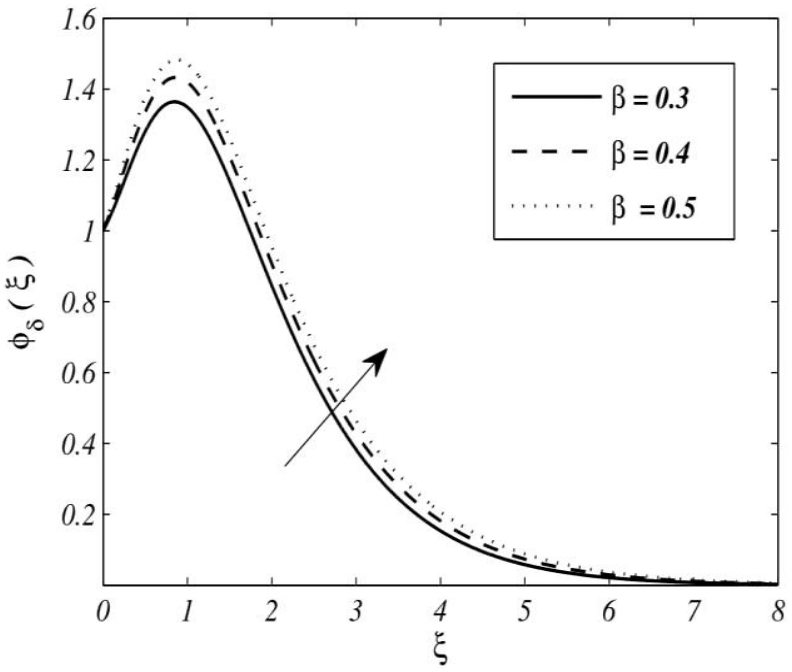

Figure 16: Impact of Casson fluid parameter $\beta$ on concentration profile $\phi_{\delta}(\xi)$ for $m=1.0, \operatorname{Pr}=$ 5.0, $d=0.1, N t=N b=0.3, E c=0.1, S c=$ $1.5, N=M=1.0$

Figure 15 portraits variation for temperature distribution against non-linear stretching parameter $N$. Momentum boundary layer thickness decreasing with increasing non linearity behavior of stretching sheet that will enhances thickness of thermal boundary and therefore fluid temperature enhances for higher values of non-linear stretching parameter $N$.

Figure 16 reveals the variation of nanoparticle volume fraction under the influence of Casson fluid parameter $\beta(0.3,0.4,0.5)$. An intensification in the value of Casson fluid parameter $\beta$ results in the enhancement of viscous behavior of fluid flow. Because of this viscous nature domination, nanoparticle concentration rises as illustrated via Figure 16. Figure 16 prevailed that this effect is more pronounced for steady state flow.

Figure 17 manifests the impact of velocity slip parameter $d(0.00,0.05,0.15)$ on nanoparticle concentration $\phi_{\delta}(\xi)$. With an increase in the value of velocity slip parameter $d$, nanoparticle concentration enhances that consequently declines the numeric value of local Sherwood number as seen in Table 2. 


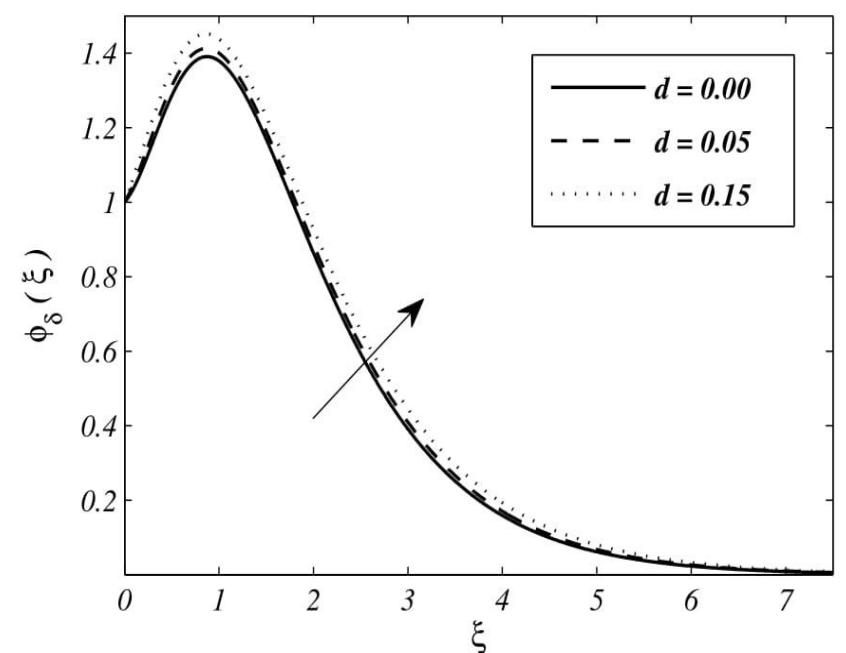

Figure 17: Impact of velocity slip parameter $d$ on concentration profile $\phi_{\delta}(\xi)$ for $m=1.0, \operatorname{Pr}=$ 5.0, $\beta=0.4, N t=N b=0.3, E c=0.1, S c=$ $1.5, N=M=1.0$

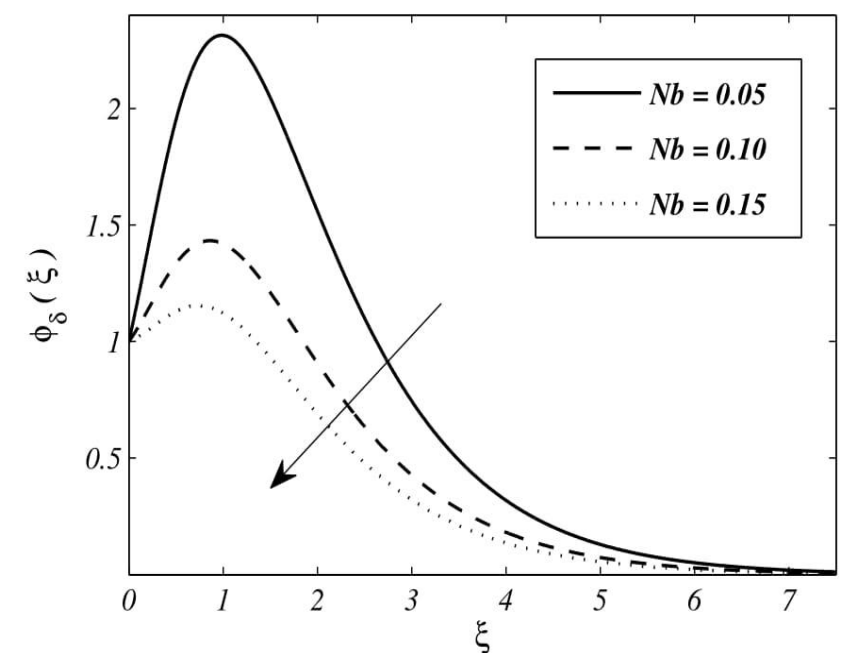

Figure 18: Impact of Brownian motion parameter $\mathrm{Nb}$ on concentration profile $\phi_{\delta}(\xi)$ for $m=1.0, \mathrm{Pr}=$ $5.0, \beta=0.4, d=0.1, N t=0.3, E c=0.1, S c=$ $1.5, M=N=1.0$

Figure 18 manifests the impact of Brownian motion parameter $N b(0.05,0.10,0.15)$ on nanoparticle concentration $\phi_{\delta}(\xi)$. With an increase in the value of Brownian motion parameter $\mathrm{Nb}$, fluid particles collides with each other with higher speed which results in increase in the nanoparticle concentration and consequently, local Sherwood number reduces as depicted in the Table 2.

Figure 19 portraits variation for nanoparticle volume fraction $\phi_{\delta}(\xi)$ against thermophoresis parameter $N t(0.2,0.3,0.4)$. This graph shows that with an increase in thermophoresis parameter, nanoparticle concentration increases. Basically, in case of thermophoresis force applied by a particle on the other particle will generates the movement of particles from hotter to colder part and hence fluid moves from hotter to colder region and hence intensification in the nanoparticle volume fraction is observed via Figure 19.

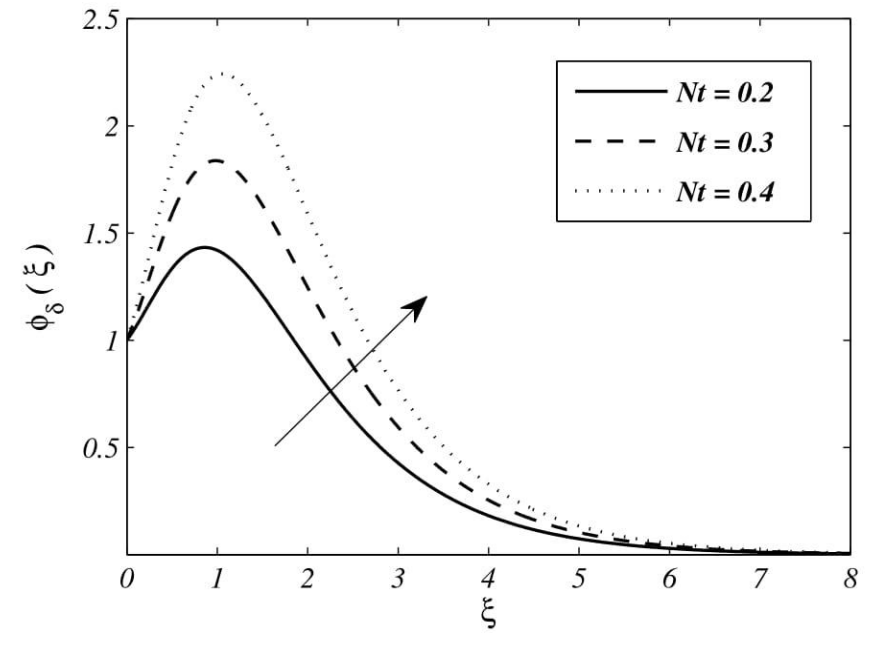

Figure 19: Impact of thermophoresis parameter $N t$ on concentration profile $\phi_{\delta}(\xi)$ for $m=1.0, \operatorname{Pr}=$ 5.0, $\beta=0.4, N b=0.3, d=0.1, E c=0.1, S c=$ 1.5, $N=M=1.0$

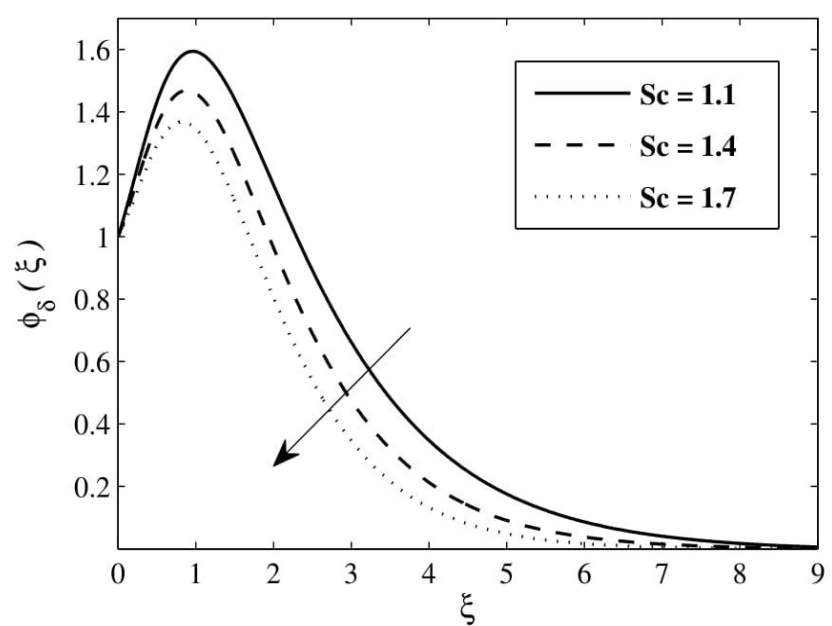

Figure 20: Impact of Schmidt number $S c$ on concentration profile $\phi_{\delta}(\xi)$ for $m=1.0, \operatorname{Pr}=$ $5.0, \beta=0.4, d=0.1, N t=0.3, E c=0.1, N b=$ $0.3, M=N=1.0$ 


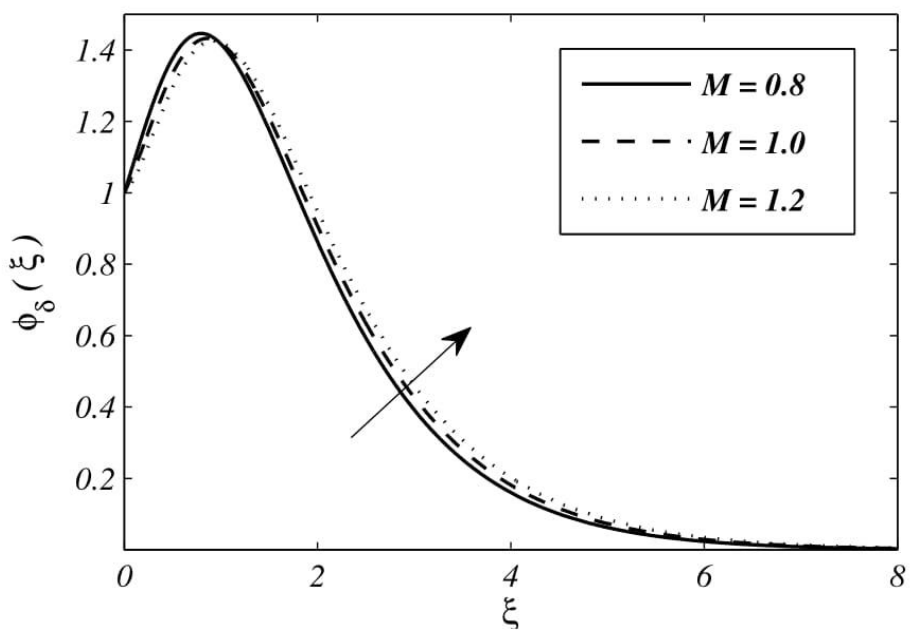

Figure 21: Impact of magnetic parameter $M$ on concentration profile $\phi_{\delta}(\xi)$ for $m=1.0, \operatorname{Pr}=5.0, \beta=0.4, d=$

$$
0.1, N t=N b=0.3, E c=0.1, S c=1.5 \text { and } N=1.0
$$

Figure 20 portraits the impact of Schmidt number $S c(1.1,1.4,1.7)$ on profile of nanoparticle concentration. Intensification in the value of physical parameter Sc, declination in mass diffusivity is observed. Due to this effect nanoparticle concentration decreases. Figure 21 reflects the variation for nanoparticle concentration $\phi_{\delta}(\xi)$ against the magnetic parameter $M(0.8,1.0,1.2)$. With increase in magnetic parameter $M$, rate of mass transportation decreases that consequently increase nanoparticle concentration and hence reduction in the value of local Sherwood number is notice as seen in Table 2.

\section{CONCLUSION}

Present study reflects the heat, mass and flow transportation of Magnetohydrodynamic (MHD) Casson nanofluid towards a sheet which is stretched non-linearly. Final outcomes of the current study incorporates the significance of Ohmic and Viscous dissipation effects in addition to the MHD Casson fluid flow velocity profile, temperature distribution and nanoparticle volume fraction. Similarity conversion is used for transforming partial into ordinary differential equations. Key findings of current analysis are summarized as:

1. Skin friction coefficient elevates with increment in magnetic parameter $M$ due to produced Lorentz force that ultimately improves local Sherwood number along with Nusselt number for higher magnetic parameter $M$.

2. A declination in the value of Velocity profile is observed with variation in the values of Casson fluid parameter $\beta$, velocity slip parameter $d$ whereas rises for larger values of non-linear stretching parameter $N$.

3. Fluid temperature enhances for greater values of physical parameters Eckert number $E c$, Brownian motion parameter $N b$ and thermophoresis parameter $N t$. On the other hand, it reduces for higher values of Casson fluid parameter $\beta$ and velocity slip parameter $d$.

4. An enhancement in the profile of nanoparticle concentration is noticed for greater values of thermophoresis parameter $N t$, velocity slip parameter $d$, Casson fluid parameter $\beta$. Whereas, it declines for Brownian motion parameter $N b$ and Schmidt number $S c$.

It is hoped that current analysis serves impetus for the scientists to develop technological applications over stretching surfaces. Results of the present study helps to control heat transfer rate in different manufacturing processes, biological systems to produce the quality product this analysis can be extended to shrinking surface as well. 


\section{NOMENCLATURE}

$\begin{array}{ll}x, y & \text { Cartesian coordinates } \\ B & \text { Magnetic field intensity } \\ U & \text { Stream velocity } \\ a & \text { Positive constant } \\ m & \text { Surface temperature parameter } \\ S c & \text { Schmidt number } \\ C & \text { Concentration } \\ C_{w} & \text { Nanoparticle volume fraction } \\ q_{m} & \text { Mass flux } \\ P r & \text { Prandtl number } \\ N u_{x} & \text { Nusselt number } \\ N t & \text { Thermophoresis parameter } \\ T_{\infty} & \text { Ambient temperature attained } \\ S h_{x} & \text { Sheerwood number } \\ v & \text { Vertical velocity } \\ D_{B} & \text { Brownian diffusion coefficient } \\ N b & \text { Brownian motion parameter } \\ N & \text { Non linear stretching parameter } \\ T & \text { Temperature } \\ u_{w} & \text { Stretching velocity } \\ D_{T} & \text { Thermophoresis diffusion coefficient } \\ u_{s} & \text { Slip velocity } \\ l & \text { Slip length } \\ T_{w} & \text { Temperature at the sheet } \\ q_{w} & \text { Hass flux } \\ C_{\infty} & \text { Ambient nanoparticle volume fraction } \\ u & \text { Horizontal velocity } \\ M & \text { Magnetic parameter } \\ & \end{array}$

Greek symbols

$v$
$\beta$
$\sigma$
$\xi$
$\rho_{f}$
$\alpha_{m}$
$\tau$
$\theta_{\delta}$
$\phi_{\delta}$

Kinematic viscosity

Casson fluid parameter

Electrical conductivity

Similarity variable

Density of base fluid

Thermal diffusivity

Ratio of heat capacities

Non-dimensional temperature

Non-dimensional nanoparticle concentration

Subscripts

$p \quad$ Particle

$\infty \quad$ Ambient condition

$f \quad$ Fluid

$w \quad$ Wall

Superscript

( ) $)^{\prime} \quad$ Prime denotes derivative w.r.t $\xi$

\section{ACKNOWLEDGEMENT}

First author (Vinita) would like to thank Mr. Madan Lal Makkar and Mrs. Neelam Makkar for their love, support and encouragement. Additionally, all authors appreciate the constructive and valuable comments of the reviewers, which improved the manuscript. 


\section{REFERENCES}

[1] Crane LJ. Flow past a stretching plate. Zeitschrift fr angewandte Mathematik und Physik ZAMP 1970; 21: 645647.

[2] Gupta PS, Gupta AS. Heat and mass transfer on a stretching sheet with suction or blowing. The Canadian Journal of Chemical Engineering 1977; 55: 744-746.

[3] Yoon BB, Rao RS, Kikuchi N. Sheet stretching: A theoretical-experimental comparison. International Journal of Mechanical Sciences 1989; 31: 579-590.

[4] Sarma MS, Rao BN. Heat transfer in a viscoelastic fluid over a stretching sheet. Journal of Mathematical Analysis and Applications 1998; 222: 268-275.

[5] Vajravelu K. Viscous flow over a nonlinearly stretching sheet. Appl. Math. Comput. 2001; 124: 281-288.

[6] Cortell R. Viscous flow and heat transfer over a nonlinearly stretching sheet. Applied Mathematics and Computation 2007; 184: 864-873.

[7] Nadeem S, Hussain A, Vajravelu K. Effects of heat transfer on the stagnation flow of a third order fluid over a shrinking sheet. Zeitschrift fr Naturforschung A 2010; 65: 969-994.

[8] Prasad K, Vajravelu K, Datti P. Mixed convection heat transfer over a non-linear stretching surface with variable fluid properties. International Journal of Non-Linear Mechanics 2010; 45: 320-330.

[9] Choi SUS, Eastman JA. Enhancing thermal conductivity of fluids with nanoparticles. ASME International Mechanical Engineering Congress and Exposition 1995: 1-9.

[10] Buongiorno J. Convective transport in nanofluids. Journal of Heat Transfer 2006; 128: 240-250.

[11] Kuznetsov A, Nield D. Natural convective boundary-layer flow of a nanofluid past a vertical plate. International Journal of Thermal Sciences 2010; 49: 243-247.

[12] Mamaloukas C, Spartalis S, Mazumdar HP. MHD flow of a Newtonian fluid over a stretching sheet: an approximate solution. International journal of Computational and Numerical Analysis and Applications 2002; 1: 299-310.

[13] Tamizharasi R, Kumaran V. Pressure in MHD/Brinkman flow past a stretching sheet. Communications in Nonlinear Science and Numerical Simulation 2011; 16: 4671-4681.

[14] Hayat T, Qasim M, Mesloub S. MHD flow and heat transfer over permeable stretching sheet with slip conditions. International Journal for Numerical Methods in Fluids 2011; 66: 963-975.

[15] Hussain A, Malik M, Salahuddin T, Bilal S, Awais M. Combined effects of viscous dissipation and joule heating on MHD sisko nanofluid over a stretching cylinder. Journal of Molecular Liquids 2017; 231: 341-352.

[16] Vajravelu K and Cannon J. Fluid flow over a nonlinearly stretching sheet. Applied Mathematics and Computation 2006; 181: 609-618.

[17] Matin MH, Nobari MRH, Jahangiri P. Entropy Analysis in Mixed Convection MHD flow of Nanofluid over a Non-linear Stretching Sheet. Journal of Thermal Science and Technology 2012; 7(1): 104-119.

[18] Shawky HM, Eldabe NTM, Kamel KA, Abd-Aziz EA. MHD flow with heat and mass transfer of Williamson nanofluid over stretching sheet through porous medium. Microsystem Technologies 2019; 25: 1155-1169.

[19] Basir MFMd, Uddin MJ, Ismail AIMd, Bg OA. Nanofluid slip flow over a stretching cylinder with schmidt and pclet number effects. AIP Advances 2016; 6: 1-15.

[20] Pandey AK, Kumar M. Boundary layer flow and heat transfer analysis on cu-water nanofluid flow over a stretching cylinder with slip 2017; 56(4): 671-677.

[21] Vinita V, Poply V. Impact of outer velocity MHD slip flow and heat transfer of nanofluid past a stretching cylinder. Materials Today: Proceedings 2020; 26: 3429-3435.

[22] Vinita, Poply V, Goyal R, Sharma N. Analysis of the velocity, thermal, and concentration MHD slip flow over a nonlinear stretching cylinder in the presence of outer velocity. Heat Transfer 2020; 1-27. https://doi.org/10.1002/htj.21941.

[23] Goyal R, Vinita, Sharma N, Bhargava R. GFEM analysis of MHD nanofluid flow toward a power-law stretching sheet in the presence of thermodiffusive effect along with regression investigation. Heat Transfer 2020; $1-23$. https://doi.org/10.1002/htj.21873.

[24] Poply V, Singh P, Choudhary KK. Analysis of laminar boundary layer flow along a stretching cylinder in the 
presence of thermal radiation. WSEAS Trans Fluid Mech. 2013; 8: 159-164.

[25] Rana P, Bhargava R. Flow and heat transfer of a nanofluid over a nonlinearly stretching sheet: A numerical study. Communications in Nonlinear Science and Numerical Simulation 2012; 17: 212- 226.

[26] Casson N. In rheology of dispersed system, pergamon press, oxford, uk, 1959," 1959.

[27] Mustafa M, Hayat T, Pop I, Aziz A. Unsteady boundary layer flow of a Casson fluid due to an impulsively started moving flat plate. Heat Trans. Asian Res. 2011; 40: 563-576.

[28] Nadeem S, Mehmood R, Akbar NS. Optimized analytical solution for oblique flow of a Casson nano fluid with convective boundary conditions. International Journal of Thermal Sciences 2014; 78: 90-100.

[29] Poply V, Vinita (2021). Analysis of Outer Velocity and Heat Transfer of Nanofluid Past a Stretching Cylinder with Heat Generation and Radiation. In: Singh P., Gupta R.K., Ray K., Bandyopadhyay A. (eds) Proceedings of International Conference on Trends in Computational and Cognitive Engineering. Advances in Intelligent Systems and Computing, vol 1169. Springer, Singapore. https://doi.org/10.1007/978-981-15-5414-8_18

[30] Oyelakin IS, Mondal S, Sibanda P. Unsteady Casson nanofluid flow over a stretching sheet with thermal radiation, convective and slip boundary conditions. Alexandria Engineering Journal 2016; 55: 1025-1035.

[31] Oyelakin I, Mondal S, Sibanda P. Unsteady MHD three dimensional Casson nanofluid flow over a porous linear stretching sheet with slip condition. Frontiers in Heat and Mass Transfer 2017; 8: 1-9.

[32] Oyelakin IS, Mondal S, Sibanda P. Nonlinear radiation in bio-convective Casson nanofluid flow. Int. J. Appl. Comput. Math 2019; 5: 1-20.

[33] Almakki M, Mondal H, Sibanda P. Entropy generation in MHD flow of viscoelastic nanofluids with homogeneous-heterogeneous reaction, partial slip and nonlinear thermal radiation. Journal of Thermal Engineering 2020; 327-345, doi: 10.18186/thermal.712452.

[34] Geridönmez BP. Numerical simulation of natural convection in a porous cavity filled with ferrofluid in presence of magnetic source. Journal of Thermal Engineering 2017; 4(2): 1756-1769, doi: 10.18186/journal-of-thermalengineering.369169.

[35] Poply V, Singh P, Yadav AK. A study of temperature-dependent fluid properties on mhd free stream flow and heat transfer over a non-linearly stretching sheet. Procedia Engineering 2015; 127: 391 - 397.

[36] Singh P, Poply V. Impact of free stream velocity and variable heat flux over a permeable stretching surface. International Journal of Applied Engineering Research 2015; 10: 69-76.

[37] Kameswaran PK, Shaw S, Sibanda P. Dual solutions of Casson fluid flow over a stretching or shrinking sheet. Sadhana 2014; 39: 1573-1583.

[38] Khan MS, Karim I, Ali LE, Islam A. Unsteady MHD free convection boundary-layer flow of a nanofluid along a stretching sheet with thermal radiation and viscous dissipation effects. Int Nano Lett 2012; 2: 1-9.

[39] Afify AA. The influence of slip boundary condition on Casson nanofluid flow over a stretching sheet in the presence of viscous dissipation and chemical reaction. Mathematical Problems in Engineering 2017; 2017: 1-12.

[40] Mustafa M, Khan JA. Model for flow of Casson nanofluid past a non-linearly stretching sheet considering magnetic field effects. AIP Advances 2015; 5: 1-11.

[41] Usman M, Soomro FA, Haq RUI, Wang W, Defterli O. Thermal and velocity slip effects on Casson nanofluid flow over an inclined permeable stretching cylinder via collocation method. International Journal of Heat and Mass Transfer 2018; 122: 1255-1263.

[42] Gireesha B, Srinivasa C, Shashikumar N, Macha M, Singh J, Mahanthesh B. Entropy generation and heat transport analysis of Casson fluid flow with viscous and Joule heating in an inclined porous microchannel. Proceedings of the Institution of Mechanical Engineers, Part E: Journal of Process Mechanical Engineering 2019; 233: 11731184.

[43] Seth GS, Bhattacharyya A, Kumar R, Chamkha AJ. Entropy generation in hydro-magnetic nanofluid flow over a non-linear stretching sheet with Naviers velocity slip and convective heat transfer. Physics of Fluids 2018; 30: 115. 